\title{
Receptores de Estrogeno y de Progesterona en el tratamiento del cáncer mamario
}

\author{
Revisión de conjunto de los conocimientos actuales \\ Dr. Elmer Pinilla Galvis *
}

\section{introducción}

Cada día adquieremás importancia la demostración de los receptores de estrógenos y de progesterona como método de selección y de pronóstico en el tratamiento del cáncer de la mama.

En este artículo se hace una revisión de conjunto del estado actual de los conocimientos al respecto según los investigadores, entre 1975 y 1978.

\section{Breve reseña histórica.}

Desde hace tiempo se sabe que muchos cánceres mamarios son "hormonodependientes", es decir, que su crecimiento está influido por los niveles de las hormonas sexuales, y que tales tumores regresan luego de la extirpación de las glándulas que secretan las homonas de soporte.

En 1836, Cooper observó relación entre el crecimiento tumoral y el ciclo menstrual. En 1896, Beatson informó regresiones de la metástasis después de ooforectomía en premenopáusicas con cáncer mamario avanzado.

En 1956, Huggins y Bergenstal informaron remisiones similares después de adrenalectomía, y, posteriormente, Luft, Pearson y Ray comprobaron iguales resultados con la hipofisectomía.

Actualmente, la deprivación hormonal, mediante la extirpación de las glándulas endocrinas, es el tratamiento más efectivo para el cáncer hormonodependiente de la glándula mamaria. Desafortunadamente, no todos estos tumores responden a la extirpación endocrina, por lo cual es necesario po-

Departamento de Ginecología y Obstetricia.

Hospital Universitario de San Vicente de Paúl. Medellín.

Profesor Asociado I

Facultad de Medicina de la Universidad de Antioquia. seer alguna manera de descubrir cuáles tumores hormonodependientes no van a responder a ese tratamiento para que la terapia endocrina se restrinja solamente a los que sí lo harán.

En 1967, Jeusenbasado en los conocimientos que se tenían sobre los receptores hormonales, postuló la idea de relacionar los niveles de los receptores de estrógenos en especímenes de tumores mamarios malignos con la respuesta clínica al tratamiento endocrino, para seleccionar, en esa forma, el tratamiento adecuado: terapia endocrina para los tumores sensibles a ella, y quimioterapia a los tumores "independientes" de la acciṕn hormonal.

\section{Receptores de estrogenos}

Las hormonas son sustancias de "información"; son verdaderas "mensajeros: químicos, que vana encontrar en las células de los tejidos el "blanco" de su acción, los mecanismos específicos que los van a reconocer y a seleccionar, también específicamente, de entre todos los demás componentes del medio interior. El principal componente de esos mecanismos de reconocimiento y selección en la célula, recibe el nombre de RECEPTOR. La unión del receptor con la hormona es un fenómeno puramente físico en el cual la hormona no sufre ninguna alteración, aunque el receptor sí, como se verá más adelante.

Al administrar estradiol marcado con un isótopo radiactivo a las ratas, la hormona se concentra en los órganos "blanco" de su acción (útero, adenohipófisis, hipotálamo) y esas concentraciones dependen de los niveles plasmáticos de los estrógenos endógenos. Esto significa que, si se aumenta la dosis de estradiol marcado, no necesariamente hay un aumento de su concentración en los órganos mencionados, lo cual quiere decir que el sistema de acumulación del estrógeno exógeno tiene una capacidad condicionada. 
La acumulación del estrógeno exógeno en las células del órgano "blanco" se debe al RECEPTOR, el cual es una proteina citoplasmática que tiene una gran afinidad y una alta especificidad estrogénicas, y al que Jensen dió el nombre de ESTROFILINA.

La estrofilina es una macroproteina de peso molescular de 80.000 que capta estrógenos en proporciones diferentes: el de mayor índice de unión es el estradiol al cual siguen, en orden decreciente, el 17Betinilestradiol, el dietilestilbestrol, la equilina y la estrona. Según parece, cuando el estrógeno posee un radical hidroxilo en posición 3 , aumenta considerablemente su capacidad de unión.

El significado exacto de la idea de RECEPTOR implica que debe haber una "señal", (la hormona), una "interpretación" de ella y una respuesta celular, pues en el plasma hay también proteinas con capacidad de enlaces específicos y de alta afinidad, como la transcortina, que capta cortisol y progesterona, pero cuya función es más bien de "transporte".

\section{Cantidad de enlace}

Se ha establecido que la cantidad del estrógeno que se une a la proteina receptora varía entre 10.000 y 100.000 moléculas de aquél por cada célula del órgano "blanco" $o$, lo que es igual, entre 0.0 y 1.000 fentomoles de estrógenos por miligramo de proteina receptora.

Esta enorme diferencia de la cantidad de enlaces se debe a la gran heterogeneidad de los tumores, más específicamente de sus células que contienen el receptor.

\section{Mecanismo de acción}

El estrógeno penetra al interior de la célula por difusión pasiva a través de la membrana celular y es captado en el citoplasma por la proteina receptora específica, la estrofilina. Esta proteina, antes de unirse con el estrógeno, sedimenta a la ultracentrífuga en 8 unidades Swelberg; pero, una vez hecho el enlace con el estrógeno, se transforma en otra proteina de menor peso molecular que sedimenta en 5U.S.

El complejo estrógeno-receptor, por translocación, penetra dentro del núcleo y se localizar en un sitio aceptor de la cromatina donde desencadena una estimulación de la actividad RNA polimeraza con aumento de la síntesis de ácidos nucléicos y de proteinas, con lo cual se ejecuta el efecto biológico. Si la cadena de acontecimientos tiene algún defecto en uno cualquiera de sus eslabones (receptor-translocación-núcleo), la célula no responde a la acción de la hormona y no hay efecto biológico. Adicionalmente, otras actividades que también parecen ser inducidas, son la síntesis de receptores adicionales de estrógenos en el citoplasma así como la síntesis de receptores de progesterona.

Luego de obtenida la respuesta celular, el efecto biológico, la hormona abandona el receptor y se degrada, lo cual explica porqué la secreción hormonal es continua para que se permita su renovación.

Jensen ideó una prueba in vitro para demostrar o no la presencia del receptor de estrógenos y, mediante ella, se han demostrado proteinas receptoras en endo y miometrio, en cérvix uterino, en trompas de Falopio, en adenocarcinomas de endometrio y en 50 a $75 \%$ de los carcinomas de la mama.

Diferentes receptores para diferentes hormonas en la misma célula.

El hecho de que el estradiol pueda inducir no soloreceptores de estrógenos, sino de progesterona, indica que en una misma célula puede haber distintos receptores para distintos hormonas.

Diferentes receptores para una misma hormona en diferentes "células blanco"

No se sabe aún si los receptores de estrógenos son los mismos en endometrio, en miometrio, en mucosa cervical, en el hipotálamo, en la hipófisis en la glándula mamaria normal y en la patológica, es decir, en diferentes "células blanco". Pero hay un ejemplo de que una misma hormona puede efectuar su acción biológica a través de diferentes receptores sobre diferentes tejidos blanco: la testosterona puede actuar como testosterona misma en el riñón y en el elevador del ano; como androstenolona (dihidrotestoterona) en la próstata veníral y en las vesículas seminales, y como estrógeno en el hipotálamo. 
Diferentes receptores para la misma hormona en la misma célula

Experimentalmente se han inducido tumores mamarios en ratas androgenodependientes en cuyas células hay receptores de andrógenos y receptores de estrógenos. Los receptores de estrógenos enlazan estrógenos con gran especificidad pero no andrógenos; en cambio los receptores de andrógenos captan con gran afinidad andrógenos, pero también, aunque con menos especificidad, estrógenos.

Variaciones en los niveles del receptor de estrógenos.

Ya se vió que las concentraciones de los estrógenos en el citoplasma variaba ampliamente entre 0.0 y 1.000 f.molxmgr de proteina receptora. Tal divergencia se debe a varios factores.

1. La calidad de células tumorales que contengan el receptor.

2. La cantidad de receptor presente en cada célula.

3. Los niveles plasmáticos de los estrógenos endógenos: si son altos, penetran al citoplasma e inundan los receptores que hay inutilizándolos para su investigación; o los translocan al núcleo donde se hace difícil su investigación por los métodos actuales. Brooks demostró la aparición de receptores en ratas después de ooforectomía, lo cual indica que los altos niveles de estrógenos endógenos ocupan los receptores. Esto puede explicar la relación entre la edad, o estado pre o posmenopáusico, y la concentración de los receptores de estrógenos, pues se observa que en premenopáusicas que tienen niveles altos de ustrogenos endogenos, hay menor proporción de tumores con receptores y menores concentraciones de éstos, mientras que en las posmenopaúsicas hay mayor cantidad de tumores con receptor y éste se halla en mayor concentración.

3. El tipo de tejido obtenido para la valoración: el tumor primario es más frecuentemente positivo $(77 \%)$ que el metastásico $(66 \%)$, lo cual se debe a que las células neoplásicas se van volviendo cada vez más indiferenciadai y van perdiendo el control endocrino a medida que la enfermedad avanza.
4. Concomitancia de Células positivas y células negativas: si el tumor primario posee a la vez ambos tipos de células, hay predomino de las negativas que tienen mayor capacidad proliferativa.

5. Diferenciación tumoral: entre más indiferenciado es el tumor, sus células son más negativas. Los diferenciados como el lobulillar, son de células positivas.

6. Reacción linfocitaria: los tumores que la presentan, son negativos. Como los estrógenos, tienen la capacidad de inducir sus receptores, es posible que un tumor mamario que no muestra receptores de estrógenos en sus células ( $R E$-) se puede volver $\mathrm{RE}+$ mediante un tratamiento adecuado con estrógenos, los cuales van

a ocupar los sitios dejados por el receptor y a inducir su síntesis.

\section{Calificación de positividad o negatividad}

Con la experiencia clínica adquirida, se ha podido establecer ya que los niveles mínimos para considerar que un tumor mamario maligno es $\mathrm{RE}+$ son de 2.5 f.mol.x mgr de proteina receptora. Jensen divide los tumores según la concentración del receptor así:

Estrofilin $\left\{\begin{array}{r}\text { más de } 750 \text { f.molxmgr-1 Posme- } \\ \text { nopáusicas Castradas } \\ \text { más de } 250 \text { f.molxmgr-1 Preme- }\end{array}\right.$

nopáusicas

Estrof.
límites entre 450-750 ", , $\begin{aligned} & \text { " Posme- } \\ & \text { entre 150-250 }\end{aligned}$

Estrof. negativos: Por debajo de las cifras anteriores.

\section{Receptores de progesterona}

Aproximadamente una tercera parte de los tumores mamarios malignos $\mathrm{RE}+$ son autónomos, no se modifican con la terapia endocrina. Su carácter independiente se debe a alguna falla de la cadena receptor-translocación núcleo por un receptor defectuoso, por anomalías en la translocación o por fenómenos nucleares anormales. Es imporportante saber entonces, que tumores RET son autónomos para que, con los RE-, caigan en el campo de la quimioterapia directamente. Ello es posible gracias a los recep- 


\section{tores de progesterona.}

Para que haya un efectio biológico de carácter progestacional sobre un tejido, es indispensable que este tejido haya sido preparado previa y adecuadamente por los estrógenos. Como la presencia de los receptores de progesterona son una etapa final de la acción de los estrógenos, su descubrimiento indica una vía intacta de la acción estrogénica y una vía intacta de respuesta a ellos.

Según McGuire, un tercido de los tumores malignos de la manama carecen del receptor (RE-); un tercio son Re +. El grupo de tumores $\mathrm{RE}+$. Los tumores RE- casi nunca son $\mathrm{RPg}+$. El grupo de tumores $\mathrm{Re}+$ $\mathrm{RPg}+$ son los que muestran el más alto índice de respuesta a la terapia endocrina ( 82 o $)$. Sin embargo, hay tumores RPg- que responden a ella, lo cual puede deberse a que son falsos RPg- por escasez de estrógenos endógenos que son insuficientes para inducir la síntesis de receptores de progesterona, y no por un defecto del mecanismo de respuesta a la acción de los estrógenos. La administración de estrógenos por un corto tiempo hace aparecer en biopsias posteriores los receptores de progesterona que no había. Otra causa de falsos RPg- se halla en el diestro de las mujeres premenopáusicas durante el cual los altos niveles endógenos de progesterona hacen que esta hormona ocupe sus receptores y no aparezcan en su investigación.

Los tumores que poseen altos niveles de concentración de proteina receptora de estrógenos tamuién poseen receptores de progesterona por lo cual su descubrimiento evita la investigación de receptores de progesterona : $82 \%$ o de los tumores malig nos de la mamá que poseen más de 100 F.mol.xmgr también tienen receptores de progesterona.

Receptores nucleares de estrógenos.

Otra alternativa para descubrir los tumores $\mathrm{Re}+$ autónomos o independientes es la investigación de la presencia de receptores nucleares de estrógenos cuya presencia en el núcleo indica también una cadena intacta. Algunos trabajos indican que la ausencia de receptores de estrógenos en el núcleo hace que los tumores sean autónomos a pesar de haber receptor de citosol. Otros trabajos muestran que hay receptores nuclea- res de estrógenos "libres" que nocaptan el esteroide. Su significación exacta se desconoce pero se postula que, en ausencia de estrógenos, el receptor citoplásmico puede translocar al núcleo y provocar en él la aparición de receptores nucleares. Estos tumores igualmente son autónomos aunque sean $\mathrm{RE}+\mathrm{RPg}+$

Como teóricamente las sustancias antiestrógenas (clomifeno, tamoxifeno, nafoxidina) puede unirse al receptor "libre y así inactivarlo, la terapia con antiestrógenos sería una alternativa para dichos tumores. Los antiestrógenos carecen de la propiedad de inducir receptores de estrógenos.

\section{TRATAMIENTO DEL CANCER MAMA- RIO SEGUN LOS RE.}

Aproximadamente un $75^{\circ}$ o de los tumores mamarios malignos que contienen la proteina receptora, estrofilina, $(\mathrm{RE}+)$, en niveles de 2.5 f.mol.x mgr, o más, responden al tratamiento endocrino y regresan. Dicho tratamiento puede ser a) por adición, o sea la administración de grandes dosis de esteroides (estrógenos, progestágenos, andrógenos, corticosteroides), y b), por supresión quirúrgica o ablación (ooforectomía en premenopáusicas y adrenalectomía e hipofisectomía en posmenopáusicas). Solamente un 5 \% de lus tumores REson hormonodependientes y responden al tratamiento endocrino.

Según Brennan, no parece que al aumentar las concentraciones del receptor haya una mayor respuesta del tumor al tratamiento. Sin embargo, Mc Guire sostiene que la respuesta aumenta con los aumentos de las concentraciones por arriba de 2.5-3 f. mol. $\mathbf{x}$ mgr así $6 \%$ de los tumnres autónomos ${ }_{4} 6 \%$ de 10 s que tienen concentraciones medias, y $81 \%$ de los que tienen altas concentraciones.

De lo anterior se deduce que, dado que un $25 \%$ de los tumores Re + son autónomos, así como el $95 \%$ de los Re-, y de que todos estos tumores no respponden a la terapia endocrina, es mucho más importante descrubir estos casos para que caigan sin demora bajo la quimioterapia y no se pierda el tiempo y se eviten las consecuencias de la terapia ablativa que no los beneficia en absoluto. Se ha establecido, pues, que los tumores Ret, luego de la mastectomía, 
se tratan con métodos endocrinos, y que los Re- se tratan con quimioterápicos. Mc Guire ideó un esquema sencillo y que ha practicamente no requiere explicación: (Tabla .1.). ceptores, la selección de los casos era puramente clínica: pacientes con intervalo libre de enfermedad largo, mujeres de más de un año de menopausia y menores de 65 años en el momento de la metástasis, junto a jóvenes a quienes una ooforectomía previa

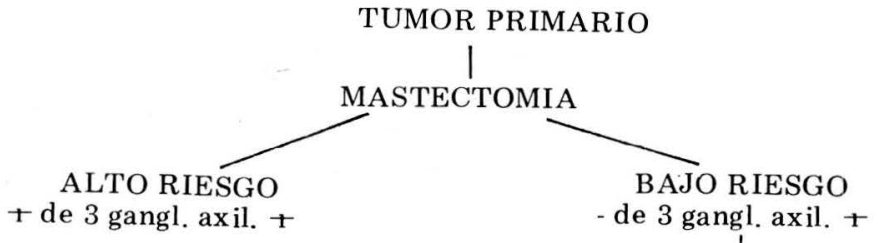

VALORACION DE RE

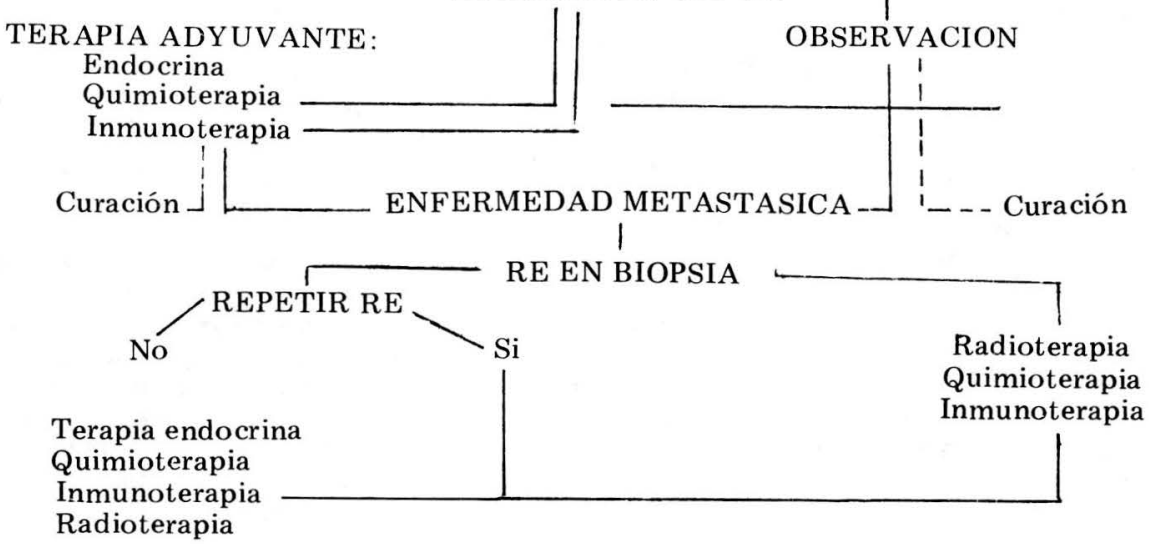

'Tabla 1.

Las consideraciones terapéuticas mencionadas incluyen mujeres pre y posmenopáusicas pero no contemplan a aquellas que se hallan en su perimenopausia, con síntomas vasomotores y oligomenorreas. En éste grupo la ooforectomía y la adrenalectomía son de poco beneficio. No se sabe si los RE son tan predictivos de una buena respuesta a la ablación. la práctica usual con estas mujeres es la adrenalectomía en casos $\mathrm{RE}$ T, si no hay metástasis cerebrales o hepáticas.

Según Brenna, la hipofisectomía es superior a la adrenalectomía debido a que da en promedio, 14 meses de remisión.

En U.S.A. antes del advenimiento de los re- les había dado una buena remisión, eran las candidatas a tales cirugías. Pero hoy, los receptores de estrógenos predicen mejor que cualquier otro índice clínico o de laboratorio la sensibilidad de la endocrinoterapia.

\section{LOS RECEPTORES COMO FACTOR PRONOSTICO}

El índice de recurrencia es mayor en los tumores RE-. Así a los 20 meses después de una mastectomía, $36 \%$ de los tumores REhan recurrido mientras que solo $17 \%$ de los $\mathrm{RE}+$. Esta relación se conserva si se consideran los ganglios axilares: en tumores con ganglios negativos (etapas I-II) los REtienen más recurrencia y menor intervalo libre que los $\mathrm{RE}+\mathrm{Ya}$ vimos que los tumores $\mathrm{RE}$ - tienen mayor capacidad proliferativa. 


\section{PLANEACION DEL TRATAMIENTO SEGUN LOS RE}

Después de la mastectomía, los pacientes se distribuyen en cuatro grupos de acuerdo con los receptores y con el estado de los ganglios axilares, cada uno de los cuales tiene distinto riesgo de recurrencia: de progesterona y se hace un enfoque práctico sobre tratamiento del cáncer mamario en función del estudio de dichos receptores hormonales.

Ganglios axilares Riego
Estado RE $\quad\left\{\begin{array}{lll}1-\mathrm{RE}+\mathrm{G}- & = & \text { Vigilancia } \\ 2-\mathrm{RE}+\mathrm{G}+ & = & \text { Endocrinoter. Quimioterap. } \\ 3-\mathrm{RE}-\mathrm{G}- & = & \text { Quimioterapia } \\ 4-\mathrm{RE}-\mathrm{G}+ & = & \text { Quimioterapia agresiva } \\ \text { cia } & =\end{array}\right.$

1- Grupo RE+G:

La enfermedad es poco agresiva (etapa -I-) y tiene bajo índice de recurrencia. Se puede vigilar sin tratamiento. Como alternativa, la terapia endocrina elimina aquellos pequeños porcentajes que ya tienen micrometástasis.

\section{2- Grupo $\mathrm{RE}+\mathrm{G}+$ :}

El pronóstico ya es malo. Debe considerarse el tratamiento endocrino. No hay mejoría en la supervivencia. Debe considerarse también la quimioterapia pues no todos los tumores $\mathrm{RE}+$ responden a la terapia endocrina.

\section{3-y 4-Grupos RE-G-y RE-G+:}

No se benefician con la endocrinoterapia. Son de tratamiento con quimioterápicos. Tumores agresivos con alto índice de recurrencia incluso desde las etapas I en que están confinados a la mama.

\section{RESUMEN}

Se hace una revisión de conjunto sobre receptores de estrógenos y de progesterona en el tratamiento del cáncer mamario. Se hace una explicación sobre la naturaleza de las células que actuan como "blancos" de acción hormonal; sobre la cantidad de estrógenos que pude unirse a una proteina receptora; la forma como actuan tales uniones; los diferentes receptores para diferentes hormonas con la misma célula; los diferentes receptores para igual hormona en la misma célula; variaciones de niveles del receptor; calificación de positivdad o negatividad. Igualmente se plantea el caso de los receptores

\section{SUMARY}

An overall review on strogenous and progesterone receivers in mammary cancer treatment is made. An explanation is given on the nature of the cells acting as "targets" of hormone action, on the quantity of strogenous that may join a receiver proteine, on how do such unions act, on the different receiver proteine, on how do such unions act, on the different receivers for an equal hormone in the same cell, on the receiver levels variations and on positive and negative qualification. It is also posed the progesterone receivers ase and a practical approach is done on mammary cancer treatment, in relation to the study of such hormonal receivers.

\section{BIBLIOGR AFIA}

Baulieu, E.E.: Steroid receptors and hormone rreceptivity JAMA, Oct. $27 / 75$ Vol. 23 No. 4 P. 404.

Brennan, M.J.: Endocrinology in breast cancer. Status and prospectus. Am. J. of clinical Pathol. Vol 64 No. 6 Dic. $/ 75$

Kelly, D.S.: Actividad esteroidea del tejido mamario normal y neoplásico. Clin. de Obst. y Ginec. Junio /75

Jensen, E.W.: Hormonodependency in breast cancer, J. of Steroid biochem. Vol. 7/76.

McGuire, W.L.: Selecting endocrineterapy for metastatic breast cancer. Postgraduate medicine. McGraw-Hill Inc. Vol. 59 No. 2 II/76.

Catt, K.J.: Receptores hormonales. Acta endocrinológica. 82: 3-5 1976 
Lippman, M.: Steroid receptors in human malignancy. Life Science Vol. 18 143:152 1976.

Eisenfeld, A.: Receptores de estrógenos. Clin de Obst. y Ginec. Dic./76.
Adams, J.B.: Hormonas esteroideas y cancer mamario humano. Una hipótesis. Cancer. Vol. 40 No. 1 Jul. $/ 77$

Osborn, K., McGuire, W.L.: Valoración de receptores hormonales. Clin. Quir. de N.A. Vol. 4 1978 